\title{
As Companheiras de Satã: o processo de diabolização da mulher
}

\author{
Carlos Roberto F. Nogueira *
}

A construção pela elite dirigente de uma mitologia satânica ao longo do Cristianismo, implicou em um monumental esforço de reconhecimento do inimigo, de suas formas e possibilidades de atuação, em paralelo à pia tarefa de identificação de seus agentes, ou seja, daqueles que, embora inseridos no rebanho dos fiéis, secretamente tramavam para a sua perdição.

E muitos serão chamados a encarnar este papel, dentre estes, e fundamentalmente, a mulher, repositária de um estigma ancestral que será sofisticadamente enriquecido por teólogos e eruditos medievais, culminando na cristalização do paradigma satânico: a bruxa, o nec plus ultra da perfídia e da maldade, o veículo preferencial de toda a malignidade de Satã, enfim, o feminimo em toda a sua tragicidade.

Contudo, para rastrearmos os caminhos da construção de nossa personagem, é necessário, em primeiro lugar, recuperar a história do Demònio em suas grandes linhas, para que possamos entender o papel social e cultural da identificação de seus agentes. No imaginário cristão ocidental, o Diabo detém o papel principal, determinando comportamentos e atitudes mentais, dominando o horizonte cultural e, em consequência, servindo de referencial para a aceitação ou rejeição de indivíduos ou coletividades envolvidos em comércio demoníaco.

O Diabo. Construção histórica por excelência, sua origem remonta às origens do Cristianismo, cuja cultura erudita irá retirar, de um fundo

* Profesor en la Universidade de São Paulo. 
comun de tradições folclóricas herdadas de vários grupos culturais e sistematizada sob a ótica da nova religiosidade, um personagen cada vez mais concreto, aterrorizante e poderoso, estebelecendo os seus modos de interação com a humanidade, ao par da construção da própria ortodoxia católica. Esforço de uma religião em busca de sua consolidação que se legitimava pelo reconhecimento no mundo pagão da realidade satânica, da existencia inquestionável do adversário, origem de todos os males e sofrimentos dos fiéis.

Assim, a cultura dirigente elaborará uma mitologia demoníaca -retirada de tradiçóes presentes no mundo antigo- que regirá dialeticamente ao longo dos séculos com os níveis populares de cultura, reproduzindo e retrabalhamdo os fundamentos eruditos, ao mesmo tempo em que efetuará una sistemática e meticulosa leitura da discordância, em especial de manifestações das tradições populares de acordo com uma ótica demonológica.

A origem do arquétipo do Diabo remonta à tradição hebraica. Apesar da religiosidade hebraica não conhecer a existência de um espírito maligno, o processo de expansionismo dos povos da Antiguidade, fornecerá, dentre os adversários de Jahveh, as expressões naturais da maldade, tornando supérflua qualquer encarnação do mal. Os deuses dos inimigos, por seu carácter nacional, pertencem aos seus povos e atuam como presentantes destes, apropriando-se do território conquistado e submetendo as divindades nele contidas. Ao povo vencido resta um recurso de carácter psíquico, o de lançar a responsabilidade de todos os seus males no deus vencedor, que passa a possuir um carácter maligno latente. A eventual explusão do invasor agregará uma condição de divindade caída, colocando-o explicitamente como espírito do Mal, cuja esfera de atuação espelha as desgraças anteriormente vividas.

Processo exemplarmente explicitado pela história hebraica, onde os contatos de sua tradição a partir do século VI a.c. -o Cativeiro da Babilônia- produzirão, nos séculos subsequentes, uma literatura apócrifa, provoada destes deuses malditos, onde o Cristianismo buscará inspiração para a construção da figura do Grande adversário.

Através do universalismo cristão, a figura do Diabo ultrapassará uma religiosidade de carácter nacional, assumindo o papel de Pai da desobediência, remetendo a sua existência a uma perspectiva muito mais ampla: a libre opção de todos e de cada um dos homens, entre o Bem e o Mal.

O universo inteiro passa a ser percebido como dividido entre dois reinos inexoravelmente antagônicos, o de Cristo e o do Diabo. Reinos imersos em um combate que data da Criação: Satã esforçandose de 
todos os modos para impedir a divulgação da «Boa Nova", que tem por missão destruir, definitivamente, o reino do Mal. Assim, avoluma-se a hoste demoníaca, retirada de uma leitura polarizada da tradição hebraica. Lúcifer, o filho da aurora, a estrela Vênus, associado ao rei da Caldéia, é resgatado de uma passagem de Isaías, onde o profeta escarnece da queda do rei, perguntando: "Como caístes do céu, ó Hellel, estrêla da manhã? (Isaías 14:12), convertendo-se no chefe das legiões rebeldes. Belzebú, o Baal-Zeboub, deus filisteu de Ekron (2 Reis 1:3) torna-se em principe dos demônios (em Mateus 3:22 e Lucas 11:15), junto com Asmodeu a divindade persa da tempestade - Aeshma deva (Mateus 12:24). Demônios trazidos do Oriente para formar o pamteão diabólico, aos quais serão acrescentadas as divindades greco-romanas por sua consequente redução como deuses antigos (e vencidos) à condição de entidades malignas. Em sua Segunda Epístola aos Coríntios o grande divulgados dos Evangelhos entre os gentios, Saulo de Tarso, apostrofava aos incrédulos "cujas inteligências o deus deste mundo obcecou a tal ponto que não percebem a luz do Evangelho, onde resplandece a glória de Cristo que é a imagem de Deus" (2 Cor 4:4). A ele, Paulo, caberia a tarefa de ir até as nações pagãs "para lhes abrir os olhos, a fim de que se convertam das trevas à luz e do poder de Satanás a Deus" (Atos 26:18).

Tais idéias foram fundamentais para a consolidação de um imaginário demoníaco, orientadoras de todo o processo de conversão dos pagãos, em especial, da conversão dos reinos bárbaros, cuja metodologia contribuiu decisivamente para a sistematização das mesmas.

Conversão frequentemente efetuada pelas armas, a partir da vontade dos chefes, como o caso do chefe franco Clodoveu, que promete a sua conversão e de todo o seu povo se Ele (Deus) se mostrasse mais poderoso que os velhos deuses, concedendo-lhe a vitória ${ }^{\text {. }}$

Trata-se de uma ação de catequese na qual os ensinamentos têm um papel muito reduzido, em proveito de uma insistência nos elementos apocalípticos: Deus Todo-poderoso, Cristo Juiz, o exército invencível dos anjos e a luta final entre o Senhor e o Anticristo. Conversão que implica em um revestimento de antigos mitos e tradições que passam a subsistir em uma permanência subterrânea e tolerada. Tal foi o preço de uma cristianização relativamente rápida que não se chocou com as estructuras culturais existentes. Ou seja, o êxito cristão manteve a continuidade do sagrado, onde as antigas tradições foram apresentadas como superadas

CARDINI, Franco, Magia, brujería y superstición en el Occidente medieval. Barcelona 1982, pág. 21. 
ou concluídas pelo Cristianismo, deixando margem à permanéncia e sobrevivéncia de tradições populares que conviverão por longo tempo junto com a ortodoxia ${ }^{2}$. Sistema evangelizador rentável que atenuou o trauma da conversão, mas deixando de lado todo um universo mental tradicional e consequentemente, alimentando uma situação prenhe de riscos, que comprometerá, por séculos, a efetiva cristianização européia.

O cristianismo triunfante transforma deuses e deusas, semideuses e heróis em santos, obliterando a cultura antiga, ao mesmo tempo em que divindades e espaços sagrados que não podiam ser assimilados tornamse, por desnaturacão, integrantes de um imenso cortejo demoníaco.

O principal crime de Satã era a persistência do Paganismo. Entretanto, a lgreja dos primeiros séculos era uma Igreja otimista e confiante de si mesma. Qualquer que fosse o poder de Satã, estava no poder de cada cristão Ihe fazer frente. A morte de Cristo representava a viragem definitiva, como cita o Evangelho de São João: «o príncipe deste mundo está julgado e condenado" (João 16:11). Do mesmo modo, Tertuliano, no século II, acreditava que era suficiente pronunciar o nome de Cristo para fazer o Diabo recuar (Apologeticus, XXI).

O poder de Satã e suas hostes estava em declínio, como afirmava Orígines, pois «a cada homem convertido, era um demônio acorrentado no Inferno, perdendo pois, o direito de tentar os homens" (Homilia in librum Jesu Nave, XV).

Estamos frente a uma Igreja que confia em si mesma, a exemplo de Santo Agostinho - seu maior teólogo dos primeiros tempos- que escrevia â espera de ser conduzido, a qualquer momento, à bem-aventurança na Cidade de Deus.

Enfim, esta era a perspectiva de uma Igreja jovem e militante que à ilusões diabólicas contrapunha a realidade da fé. Igreja que, à espera do triunfo final, elaborou e sistematizou a personagem do Mal, integrando-a à Queda do Homem, ao Pecado Original, à morte do Messias na cruz.

Contudo, a tão esperada Parusia não acontece, ao mesmo tempo em que, numa Europa onde a Conversão imposta de cima para baixo estava longe de ser completada, a persistência das antigas tradições abala progressivamente a autoconfiança dos clérigos, levando-os à terrível e angustiante conclusão: o Mal estava longe de ser vencido.

2 LE GoFF, Jacques, "Cultura clerical e tradições folclóricas na civilização merovíngia», Para um novo conceito de Idade Média. Lisboa 1979, págs. 207-219. 
Pouco a pouco, ao sabor das resistencias pagãs e dos movimentos heréticos, infiltra-se no espírito dos teólogos a dúvida: se o mundo na verdade não estaria sob a presidência dos demônios e se estes não teriam aliados por todas as partes, inclusiva - horror dos horrores!- no seio da comunidade cristã. A tolerância praticada enquanto o Paganismo teve força social, ou quando se pretendia converter aos povos que não conheciam o Cristianismo, é progressivamente abandonada. Se de início a Igreja dialogou e argumentou em favor de suas crenças, quando a "cristianização" foi absoluta, ao menos em um nível institucional, a autoridade eclesiástica, tendo o poder a seu serviço, passou a dividir o mundo em duas partes definidas e claramente antagônicas: os servidores de Deus e os servos do Diabo. Nas palavras de Jules Michelet, em seu precioso La Sorcière «Un enorme vazio se fez no mundo. Quem o ocupa? O demônio, diziam os cristãos, sempre e em todos os lugares o Demônio: Ubique daemon" ${ }^{3}$.

O Diabo está solto. Teólogos e eruditos deixam de sustentar que o Diabo está totalmente vencido. Se assim fosse, não haveria razão para a continuada existência da Igreja. Milhares de demônios vagavam por toda a parte, explorando cada fraqueza ou desejo. Quanto mais belo e doce fosse um aspecto da vida, sob a superfície o Demônio sordidamente trabalhava e espreitava para agarrar o desavisado. E suas principais vítimas eram os monges, que se sentiam vítimas de forças que eram incapaces de combater. Quanto mais piedosos fossem, maiores os padecimentos.

Indignada de ser tão fraca face ao poder dos demônios, a Igreja vai persegui-los de todas as maneiras e em todos os lugares. Era preciso reconhecer e identificar o inimigo. Para Richard de Saint-Victor, no século XII, os demônios eram incorpóreos, pois um homem poderia conter uma legião inteira (6.666) de demônios ${ }^{4}$.

As imagens e as representações teatrais desemvolvem e popularizam as imagens eruditas da presença e do poder demoníacos. Imagens que se tornam aterrorizantes, fazando que no século $X$, Ratherius, bispo de Verona, julgasse necessário lembrar aos seus subordinados que Satã e suas legiōes, por mais poderosos que fossem, estavam submetidos à autoridade de Deus Todo-poderoso ${ }^{5}$.

\footnotetext{
Michelet, Jules, La Sorcière, 2. a ed. París 1867, pág. 29.

${ }^{4}$ CoHn, Norman, Europe's Inner Demons. New York 1975, pág. 93.

5 lbidem, págs. 93-94.
} 
Estamos longe da certeza triunfante dos primeiros cristãos: os demônios não são mais simples inimigos externos, condenados a serem vencidos muitas e muitas vezes pelos pios sacerdotes, mas haviam invadido os menores espaços da vida e, sobretudo, haviam se introduzido na alma de cada cristão, que se sente vítima de forças que é incapaz de controlar.

Assim, a partir do século XII, assistimos a uma sistematização dogmática das idéias esparsas e contraditórias sobre a figura do Diabo. Esforço sistematizador que acrescenta uma infinita quantidade de sub-demônios aos espaços vazios deixados pelos teólogos anteriores, culminando com a autoridade de Tomás de Aquino:«A fé verdadeiramente católica determina que os demônios existem e podem causar dano mediante suas operações» (Quodlibet. XI, 10).

Por intermédio de Aquino e seus sucessores o folclore anterior se converte em rigorosa e complexa doutrina, aonde Satã preside o mundo em toda sua pompa e majestade:«Seu poder é tão grande que não há na Terra nenhuma força que possa ser comparada" (De Potentia, q. 63). Os demônios povoam o universo em profusão, cálculos são efetuados para estabelecer o seu número exato, tratados são escritos para auxiliar sacerdotes, médicos e juízes a identificar a presença do inimigo, numa escalada de terror reforçada substancialmente pelas pregações e sermões litúrgicos baseados na doutrina do poder e onipresença de um Diabo absolutamente hostil e impiedoso, cuja capacidade de malefício contra a humanidade havia crescido enormemente ${ }^{6}$.

O medo aumenta sem cessar: a crise do Feudalismo, a Peste Negra, as revoltas urbanas e camponesas, o avanço turco, a Guerra dos Cem anos e —o escândalo dos escândalos! - o Cisma do Papado, constituíam os indicios inequívocos que anunciavam a chegada do Reino de Satâ. Os homens sentem-se abandonados por Deus e os teólogos concordavam que, de um modo misterioso, tudo isto acontecia com a permissão do Senhor.

O Horror Diabolicus domina as consciências cristãs, que responsabilizam ao Diabo e aos seus agentes pelos sofrimentos da coletividade. O que explica o Salve-se quem puder! proferido en 1508, pelo pregador Geiler, na Catedral de Estrasburgo: "O que há de melhor a fazer é ficar em seu canto e enfiar a cabeça em seu buraco, que empenhar-se em

${ }^{6}$ Para maiores esclarecimentos sobre o tema ver, de nossa autoria, O Diabo no Imaginário Cristāo. São Paulo, Ática, 1986. 
seguir os mandamentos de Deus e praticar o bem para ganhar a salvação eterna!»? ${ }^{7}$.

Satã e seus demônios constituem a ameaça cotidiana, tramando para a perdição dos homens sobre os quais paira a terrivel angústia dos tormentos da perdição eterna. E sua vítima, por excelência, é a mulher, cujo pendor para o Mal possuía uma longa tradição. No Antigo Testamento, encontramos no Eclesiástico: «Toda a malícia é leve comparada com a malícia de uma mulher (25-26)». E para a Antiguidade Clássica, a cultura grega nos fornece o mito de Pandora, um presente dado aos homens por Zeus: «Um mal em que todos se deleitarão em rodear de amor para a sua própria desgraça. E estourou de rir» ${ }^{8}$.

Deste modo o Cristianismo constitui-se em um herdeiro de uma confluência de tradições misóginas, em particular as fornecidas pelo mundo greco-romano, que relegavam a mulher â condição de um ser frágil e tutelado, indigno de exercitar a sua cidadania e privar da companhia dos homens, restando-lhe apenas a sublime tarefa de trazer ao mundo os varões de que necessitava a polis para garantizar a sua continuidade.

Assim, não deve ser motivo de estranheza as palavras do Apóstolo dos Gentios: "O melhor éo homen não tocar a mulher. Todavia para evitar a fornicação, tenha cada homen a sua mulher e cada mulher o seu marido" (1 Cor. 7: 1-3).

A própria doutrina cristã apresentava-se como uma justificativa para explicar, na própria criação, as razões da submissão feminina, uma vez que o homem não foi criado pela mulher, ao contrário, a mulher é que fora criada pelo homem, o que a colocava em uma posição aprioristicamente submissa. E mais: a mulher era a introdutora do pecado, o Janua diaboli -o portão por onde entra o demônio, dos primeiros padres da Igreja- responsável direta pela condenação dos homens aos tormentos deste e do outro mundo, constituirido assim a vítima e ao mesmo tempo, a parceira consciente do Diabo.

A sexualidade era o primeiro e mais fundamental meio de perdição, mesmo na relação sancionada pela sociedade: «Um homem não deve utilizar sua mulher como uma rameira, nem a mulher deve se portar com seu marido como com um amante. Nada é mais imundo do amar a sua mulher como amante» prescrevia São Jerônimo (Adversus Jovianum, I,

\footnotetext{
7 Delumeau, Jean, La Peur en Occident (XIVÉME-XVIIIÉme siècles). París 1978, pág. 198.

${ }^{8}$ HESIODE, Les Travaux et les jours (V. 57-58). París 1972, pág. 88.
} 
49) como porta-voz da imensa maioria dos Teólogos da Igreja dos primeiros tempos.

A questão era que a Diabo conhecia a fragilidade do sexo femenino, destes seres absolutamente corporais, sendo, segundo Gregório Magno, «quase impossível sair-se puro do abraço conjugal» ${ }^{9}$. Postulações que excluíam a mulher do sacerdócio, pois o seu corpo, como justificava Santo Agostinho, constituía "um obstáculo permanente ao exercício da razão ${ }^{10}$. A argumentação insistia em que todo ser humano possuía uma alma espiritual assexuada e um corpo sexuado. No indivíduo masculino, o corpo reflete a alma, o que não é o caso da mulher, uma vez que o homem é cabalmente a imagem de Deus, mas não a mulher que, inferior ao homem deve se submeter a ele.

Posteriormente, com Tomás de Aquino, os argumentos misóginos ganham em qualidade e profundidade com o auxílio da ciência aristotélica: «A mulher foi criada ainda mais imperfeitamente que o homem, mesmo na sua alma (...). Na geração, o papel positivo é o do homem, a mulher sendo apenas um receptáculo. Verdadeiramente não há outro sexo que não o masculino. A mulher é um macho deficiente (grifo nosso). Não é então surpreendente que este débil ser, marcado pela imbecillitas de sua natureza, ceda às seduçōes do tentador, devendo ficar sob tutela» (Summa Theologica, I, quaestio 92, q. 93 e q. 99).

Desta maneira, o Cristianismo adicionou, sistematizou e racionalizou todo um misoginismo recebido da Antiguidade, que o desenvolvimento do culto à Virgem só irá acentuar —na medida em que exalta a mulher excepcional, para a qual a sexualidade femenina foi uma eterna ausente - a desqualificação da condição feminina.

Mesmo a idealização do feminino no assim chamado "amor cortês", não apresenta nenhuma relação com o cotidiano, mas ao contrário, serve de válvula de escape ao masculino dominante. Teme-se a mulher, pois teme-se a sexualidade como o meio preferencial de perdição. Por isso, no amor cortês, está contida uma homenagem «segura», tratando-se fundamentalmente de uma homenagem impessoal e idealizada, dirigida a uma personagem inacessível, o que exime o "amado" de qualquer contato físico com a realidade feminina.

- FlANDRIN, Jean-Louis, «A vida sexual dos casados na sociedade antiga. Da doutrina da lgreja è realidade dos comportamentos", in ARIÉs, PH. \& A. BÉJIN, Sexualidades Ocidentais. São Paulo 1985, págs. 135-152, pág. 136.

10 BuRRESEN, K. E., Subordination ef equivalence. Nature et rôle de la femme d'aprés Augustin et Thomas d'Aquin. París-Oslo 1968, págs. 25-114. 
$\mathrm{Na}$ idealização amorosa, a mulher toma a forma da mais suave felicidade que o homem pode conhecer, mas esta felicidade - por sua própria condição ideal-o homem nunca atinge. Em outras palavras, o amor estilizado é seguro e pode ser vivido impunemente em uma sociedade altamente patriarcalizada.

O exemplo de Petrarca é altamente esclarecedor. Amante ardoroso de Laura, angélica e irreal, no cotidiano patenteia uma profunda aversão à mulher:

«A mulher é um verdadeiro diabo, um inimigo da paz, uma fonte de impaciência, uma ocasião de disputas, da qual o homem deve se manter afastado se quiser preservar a tranquilidade... Para nós, se estivesse em nosso poder, perpetuaríamos o nosso nome pelo talento e não pelo casamento, pelos livros e não pelos filhos, com o auxílio da virtude, e não de uma mulher" ${ }^{11}$.

Desenvolvida pela cultura dirigente ao longo de todo o período medieval, a teoria da malignidade «natural» da fêmea amplifica-se ao sabor de uma pedagogia do medo, que, ao insistir ad nauseam na extraordinária expansão do poder diabólico, acentua dramaticamente a predestinação da mulher a ele:

«A fizeram varrer a casa? Sim. Façam-na varrer de novo. A fizeram lavar as tigelas? Façam-na lavar outra vez. A mandaram peneirar? Façam-na então peneirar. Ela fez a lixívia? Façam-na preparar em casa. Mas ela tem uma serva! Não importa a servente... Deixem-na fazer (a esposa), não por falta de ter quem o faça, mas para aplicar-lhe um exercício. Façam-na velar as crianças, lavar os cueiros e todo o resto. Se não a acostumais a fazer de tudo, ela se converterá em um bom pedacinho de carne. Não a abandoneis à suas alegrias, eu vos digo. Enquanto a mantiverdes ocupada, ela não permanecerá à janela e não the passarão pela cabeça outras idéias»" ${ }^{12}$.

Também como São Bernardino de Siena, outro pregador, Thomas Mürner, escrevia em 1512: "A mulher é um diabo doméstico. É comumente infiel, viciosa, fútil e namoradeira" ${ }^{13}$.

Este esforço pedagógico, levado a cabo fundamentalmente pelas ordens mendicantes, constitui-se em instrumento eficaz de cristianização,

\footnotetext{
11 Petrarca, Des Remèdes de l'une et l'autre fortune, citado por Y. Léfevre,, Histoire Mondiale de la femme. París 1966, II, págs. 213-214.

12 Monnier, Phillipe, Le Quattrocento. París 1924, II, pág. 198.

13 Delumeau, J., La Peur..., op cit., pág. 315.
} 
divulgando e popularizando uma cultura erudita até então confinada a uma elite restrita. Assim, os sermões, difundidos a partir do século XIII, além de implantarem um pânico em relação ao Diabo e aos terrores da danação eterna, difundiram e imprimiram nas consciências o medo da mulher.

«Para um só bruxo 50 bruxas ou demoníacas» ${ }^{14}$, escrevia Jean Bodin, em meados do século XVI. Este é o ponto de cruzamento entre a emergência do medo de Satã, com a conspiração de seus agentes para a perdição da Cristandade. A angustiante preocupação com as hostes demoníacas leva os homens a identificar no seio da comunidade, aqueles que concorriam para aumentar o poder do Maligno.

É aqui que encontramos a diabolização do feminino em sua total dramaticidade, expressão máxima de um longo processo de implantação nas consciências da vocação natural da mulher para o Mal. Bruxas e feiticeiras povoam o imaginário do final da Idade Média, responsáveis diretas por todas as desventuras e pesadelos que afligem a comunidade e, no interior desta, como vítima preferencial, o sexo masculino.

O universo das práticas mágicas é o universo da fêmea, seja por sua atuação ativa na Feitiçaria - que nos permite compreender o cotidiano do feminino e as tentativas de escape à realidade hostil- seja em seu caráter passivo, na Bruxaria, onde toda uma cultura dominante se insurge contra determinadas mulheres, ligando-as inexoravelmente a uma esfera demoníaca.

A Feitiçaria, originada de uma magia amatória ou erótica, amplamente praticada no mundo romano ao par de outras atividades relacionadas com o desejo feminino, como a perfumaria e a fabricação de venenos, contém na etimologia da sua palavra o conceito de fatum-destino. Destino que envolve todo o drama da mulher e as reações possiveis do desejo que the era sufocado, expresso arquetipicamente pelas duas filhas de Hécate: Circe e Medea.

Em Circe encontramos o poder da sedução, ou a temível força feminina, que através do encanto, fazia dos homens o que bem entendesse, inclusive reduzindo-os à condição animalesca. Medea, por sua vez,

${ }^{14}$ BODIN, Jean, «Réfutation des opinions de Jean Wier», in Démonomanie des Sorciers. París 1580, pág. 225. 
nos esclarece sobre a tragicidade feminina e os terriveis perigos de um erotismo frustrado que leva à vingança passional.

Desde a Antiguidade Clássica a atuação da feiticeira concentrava-se básicamente na fabricação de poções e na manipulação de substâncias destinadas à confecção de venenos, perfumes e encantamentos, destinados a solucionar os males de amor. Amor condenável, uma vez que se trata do amor-paixão, que intoxica o homem, levando-o a se descuidar dos seus deveres terrenos para com o príncipe e acima de tudo de cumprir os ditames do Criador.

É assim que pode ser entendido o papel do filtro mágico em Tristão $e$ Isolda, responsável pela aproximação ilegítima dos amantes através de uma paixão, e a quebra da ordem, enquanto ato de rebeldia ao senhor legítimo. Contra esta possibilidade escreve Nicolás Eyemerich, em seu Manual dos Inquisidores: «Esta questão dos filtros é de enorme importância, pois hoje em dia se administram muitos destes filtros... Os que chegam a cair em conflitos amorosos, com frequência acabam propondo a seus amantes poções de amor, para inflamá-los. Quem se acha dominado pelo desejo, pemsa que com isto, reduz à sua vontade a castidade da pessoa desejada" ${ }^{15}$.

Personagens de um mundo de desejo, aceito e ao mesmo tempo rejeitado, como pode ser observado pela legislação laica no período medieval, as feiticeiras acumulam as funções de curandeiras e parteiras, únicos terapeutas permitidos e acessíveis às mulheres, uma vez que a técnica cirúrgica concentrava-se em raparar os danos provocados pelos combates e os poucos médicos existentes eram em sua maioria judeus.

Mas a grande importância da Feitiçaria feminina centrava-se naquilo que os teólogos imputavam à excessiva credulidade feminina: a sua performance enquanto agente de prazer - a servidora de Eros. O que pode ser atestado pelo uso consagrado na maioria das línguas ocidentais de palavras como fascínio, encantamento, sedução, entre outras, retiradas do universo da Feitiçaria e que exprimem os afeitos da atração feminina sobre o sexo oposto. Como agenciamento do prazer, esta atividade se incrementa enormemente com a reurbanização da Europa, onde as práticas mágicas reencontram as condições excelentes de propagação, pelas possibilidades existentes no mundo urbano de encontros (e desencontros) das desigualdades materiais e desejos insatisfeitos. Por outro lado, no plano psíquico, a feiticeira é a priori uma participante do mundo

${ }^{15}$ EYEMERICH, Nicolás, Directorium Inquisitorum (1376). Venetia 1607, págs. 344-345. 
do mal, dos maix baixos desejos, não podendo censurar as vontades excusas daqueles que a consultam, ao contrário do sacerdote possibilitando aos seus «fregueses" nela projetarem as ambições reprimidas por uma «auto censura» coletiva.

Nos processos sob a rubrica Feitiçaria, instruídos pela Inquisição Espanhola, podemos recuperar a iniciação de uma feiticeira: na juventude exercia a atividade de cortesã e, à medida que o passar dos anos a impossibilitavam de vender os seus favores, tranformava-se em intermediária de fantasias eróticas: «para satisfazer a las putas malas mujeres casadas o por casar ${ }^{16}$.

Como na Antiguidade, além de seus conjuros, confeccionavam venenos, enfeites e cosméticos, ingredientes extremamente necessários para auxiliar, de um modo concreto, os feitiços e invocações realizados. Mulheres pobres, que apenas «possuiam a camisa que vestiam", sob 0 disfarce de costureira de roupa branca, recebiam indivíduos de ambos os sexos em sua casa, para solucionar de um modo ou de outro os males de amor. E a maioria de sua clientela era constituída de mulheres malamadas e abandonadas, como pode ser depreendido das denúncias efetuadas por 41 pessoas em 1630, contra uma costureira viúva considerada a melhor feiticeira de Toledo, visto que detinha o supremo dom de "conseguir tudo o que queria (e possibilidade maior na sordidez do cotidiano!) em sua casa não se ficava triste!» ${ }^{17}$ Uma outra, mulher de 26 anos, buscou aprender conjuros "porque queria bem a um homem e se deixou levar pelos desejos e curiosidade ${ }^{18}$.

Enfim, no mundo da feitiçaria encontramos a síntese da sabedoria e dos absurdos da tradição popular, onde se embrenham mulheres na busca de soluções para as contradições físicas e mentais -única via de sustentação em uma realidade desesperadora- obtendo o suporte, señão adequado, ao menos psiquicamente efetivo entre a existência e o possivel.

No limite da suspeição contra o sexo feminino, encontramos a Bruxaria, construção maior do discurso misógino que elaborou o Ocidente Cristão. Para os teólogos, a Demonolatria e sua forma acabada, a Bruxaria, representam a total inversão dos valores e da ordem universal. As antigas «ilusões diabólicas» dos primeiros tempos do Cristianismo, tor37.

${ }^{16}$ Archivo Histórico Nacional (AHN), Inquisición de Toledo. Legajo 82, núm. 24, fol.

17 AHN, Inquisición de Toledo. Legajo 93, núm. 217 (15), fol. 13 (s/núm.).

${ }_{18}$ AHN, Inquisición de Toledo. Legajo 82, núm. 1, fol. 36r. 
nam-se, a partir do século $x \mathrm{~V}$, realidades diabólicas — numa redundância tâo ao gosto da escolástica- practicadas por perversas mulheres.

Ao acumular vitórias, a Igreja ampliou de tal modo o front de seus adversários ou das resistências tradicionais, que o esforço de resgatía-los para o interior da ortodoxia a partir do final do século XiII, antepôs a uma igreja instituida a ameaça de una anti-igreja. Ameaçada com a impossibilidade de concluir a obra do Redentor, a cristandade inicia um processo de purificação através da perseguição brutal e extensiva, que expiava os males da comunidade pela queima ritual dos agentes de Satã.

A bruxa renega a Cristo, nisto consistia o seu hediondo crime, sendo o restante dos malefícios apenas subprodutos de sua servidão demoníaca, da desmesurada traição ao Criador. De outro modo, o pânico com o Diabo dá origem a uma liturgia do medo, inscrita no processo de recuperação dos espaços tradicionais, deixados à margem pelo Catolicismo. É assim que na França do século XVI, Loyse Maillat, com apenas 8 anos de idade, fez os juízes acreditarem que estava possuída por 5 demônios ${ }^{19}$. Igualmente, no ano de 1628, em Würzburg, na Alemanha, três crianças, entre 8 e 12 anos, puderam confessar relações sexuais com o Demônio, sem nenhuma contestação por parte das autoridades, episódio que exemplifica magistralmente o processo de disseminação do pânico, pois 11 meses depois, na mesma região, 300 crianças entre $3 \mathrm{e}$ 4 anos de idade, corifessam aos juízes relações semelhantes! ${ }^{20}$.

$\mathrm{Na}$ questão da bruxaria, encontramos a expressão máxima do misoginismo medieval e suas repercussões. Robert Munchembled, deixou patente a relacão existente entre a caça às bruxas e a vontade de extripar os erros e superstições das comunidades rurais ${ }^{21}$. Nesta perspectiva, as mulheres do meio rural representavam o equivalente dos demonólogos $e$ juízes em sua própia comunidade, pois eram encarregadas da educação dos filhos. Tratava-se, porém, de uma educação tradicional, agora considerada ilícita aos olhos de uma ortodoxia vigilante.

É aí que os demonólogos se voltam de novo para a mulher, o portão por onde entrava o demônio dos primeiros padres. Em um estudo sobre a caça às bruxas no sudoeste da Alemanha, Erik Midelfort mostrou a

19 Boguet, Henry, Discours des Sorcières (1608). Editado por Montague Summers, London 1971, pág. 1-2.

20 LEA, Henry Charles, Materials toward a History of Witchcraft (3 vs.). New York 1975 , págs. 1185-1188.

21 MuCHEMBLED, Robert, «L'Autre Côté du Mirroir: Mythes sataniques et réalités culturelles aux XVI ème et XVII ème siècles". Annales ESC (2), (1985), págs. 288-303. 
combinação do arquétipo misógino e da realidade da condição feminina existentes na perseguição à bruxaria. Em primeiro lugar, nos séculos $x V$ e XVI, é detectada uma grande mudança social: o retardamento da idade de casamento, elevando-se para 25 a 30 anos entre os homens, e para 23 a 27 anos entre as mulheres. Ao mesmo tempo pode ser comprovada uma inequivoca tendência ao celibato, fazendo com que a proporção de mulheres solteiras eleve-se de 5 para mais de $20 \%$, configurando-se uma situação de extremo impacto para uma sociedade acostumada a ter $95 \%$ de suas mulheres casadas ${ }^{22}$. Somando-se as solteiras àquelas dejxadas sozinhas por viuvez ou abndandono, teremos mais de $30 \%$ das mulheres existentes vivendo solitárias, e portanto suspeitas - una ameaça em potencial para a coletividade.

As próprias confissões ante aos juizes dão testemunho desta situação, sob o ponto de vista das acusadas: elas se entregavam ao diabo por estarem tristes ou sozinhas. Outra evidência desta reação masculina ao brutal e "anormal» aumento da presença feminina «irregular», é fornecida pela sentença proferida contra a viúva Aghata, acusada de bruxa na localidade alemã de Horb, em 1571. Ao final do processo, a acusada foi submetida à seguinte escolha: ou a condenação ao braço secular ou ser libertada sob fiança com a condição de que ela jurasse viver tranquilamente e castamente e permanecesse dia e noite em casa de seu genro ${ }^{23}$. Recolocando-a, deste modo, sob a jurisdição masculina, os juízes esperavam resolver o problema. Ou seja, retornava-se à normalidade da base social -a familia patriarcal, onde todos, inclusive criados e servos, estavam sujeitos à tutela do senhor.

A esta situação, acrescente-se uma agravante de base fisiológica: a flagrante tendência das mulheres a sobreviverem às epidemias, em proporção $600 \%$ superior à dos homens ${ }^{24}$, o que as tornava -em uma população predisposta a encará-las como dotadas de caráter malignoelementos suspeitos de provocarem as doenças ou restringirem as mortes ao sexo masculino.

Estas considerações materiais, revestidas do discurso erudito sobre - caráter diabólico da fêmea, explicam o aparecimento ao final do século XV, da Summa Demonologica, o Malleus maleficarum, obra de

${ }^{22}$ Midelfort, H. C. E., Witch-Hunting in Southwestern Germany (1562-1684). The Social and Intellectual Foundations. Stanford 1972, pág. 184.

23 Ibidem, pág. 186.

24 Russel, J. B., A History of Witchcraft, Sorcerers, Heretics and Pagans. London 1985, págs. 114-115. 
dois zelosos dominicanos, que sintetizam toda uma longa elaboraçăo erudita sobre a malignidade feminina, ao procurarem as razões da imensa supremacia das mulheres nos cultos demoniolátricos:

\begin{abstract}
«Toda bruxaria vem da luxúria carnal, na qual as mulheres são insaciáveis. Uma coisa nunca satisfeita: a boca do útero.

(...) $\mathrm{O}$ que é a mulher além de um inimigo da amizade, uma punição inescapável, um mal necessário, uma tentaçátao natural, uma calamidade apeticivel, um delicioso dano, um mal da natureza, pintado com belas cores!

(...) Quando a mulher pensa sozinha, pensa o mal, provando que tem uma naturaleza diferente, pois em intelecto são iguais às crianças e não são capazes de entender filosofia.

(...) A razão é que ela é muito mais carnal que o homem, sendo justificável para ela a maioria das abominações carnais (...). Tudo indicado pela etimologia da palavra Femina, que provém de $F e$ e Minus, pois a mulher é sempre franca para manter e preservar a fé» ${ }^{25}$.
\end{abstract}

E seguem em sua justificativa, explicando por que só utilizam o termo bruxas - maleficarum - e não o seu correspondente masculino - maleficorum -: «E abençoado seja o Altíssimo, que até agora tem preservado o sexo masculino de um crime tão grande. Uma vez que Ele quis nascer e morrer por nós (i.e., como homem), outorgo aos homens esse privilégio" ${ }^{26}$.

E mesmo o famoso adversário da perseguição às bruxas J. Weyer, médico de Guilherme V, Duque de Clèves, escrevia em 1563 contra a crueldade dos juízes e pedia piedade para as pobres mulheres envolvidas, baseado na naturaleza inferior da mulher, pois «numerosas autoridades provavam que a mulher era mais fraca no corpo e na mente do que o homem, devendo ser menos severamente punida» ${ }^{27}$.

Considerada desde a antiguidade como conhecedora de segredos mágicos, a mulher converte-se eni um agente demoníaco - numa administradora dos execramentos do Demônio- pois o mundo em que vivia não admitia outra magia que não a diabólica. Não estamos frente a uma oposição - como frequentemente se afirma- ao Cristianismo, mas dian-

\footnotetext{
${ }^{25}$ Kramer, H. \& J. Sprenger, Malleus Maleficarum (1486), I, q.VI. London 1971, págs. 114-122.

26 Ibidem, pág. 186.

${ }_{27}$ WeYER, Johan, De Praestigiis Daemonum, et Incantationibus ac Veneficiis (1563), in H. C. Lea, Materials..., op. cit., págs. 490-532, pág. 530
} 
te da tentativa de mulheres, que procuravam incrementar as suas possibilidades de viver em um nível mágico-religioso. Em outras palavras, procuravam individualmente o que lhes era negado no plano do coletivo, o que em uma visão clerical, se explicava porque são mais curiosas em saber e esquadrinhar as coisas ocultas e desejam ser sábias "como se negassem a sua própria natureza» ${ }^{28}$.

Bruxas e feiticeiras constituíram-se nas intermediárias necesárias entre a realidade e a possibilidade, fornecendo os meios mágicos do entendimento ou da superação da existência mundana a uma coletividade que as teme, mas não pode prescindir delas. Aceitas e rejeitadas, a sociedade as acolhe ou as pune, na razão direta de seus sucessos ou desventuras, projetando nestas as responsabilidades das desgraças comunitárias, em uma tentativa de expiação da própria incapacidade de superação da contradição vivida.

Assim, completa-se o quadro evolutivo: de presa preferencial do demônio, a mulher converte-se (ou é convertida) em seu lugar-tenente. Exilado por um sistema misógino civil e religioso, o feminino - a imunda matéria- buscou superar a sua situação no universo das práticas mágicas, tentativa de escape simbólico de uma realidade hostil. Contudo, ao nível da repressão ortodoxa, os processos de bruxaria, transformarão em presença objetiva (materializada nas confissões) as ilusões -e por que não dizer decepcões? - de uma Cristandade que se sente permanentemente ameaçada pelo Mal.

${ }^{28}$ CAStañega, Fray Martín de, Tratado muy sotil y bien fundado d'las supersticiones $y$ hechicerías. Logroño 1529, (não paginado). Biblioteca Nacional, Madrid (R-11.066). 